\title{
Cela, mi padre
}

\author{
Cela, meu pai
}

\author{
Cela, my father
}

\author{
Camilo José Cela Conde \\ Universidad de las Islas Baleares - Palma de Mallorca - Espanha
}

$\diamond$

\begin{abstract}
Resumen: En 1989 escribí un libro que se llamaba Cela mi padre pocos meses antes de que le concediesen el Premio Nobel. Sin saber que iba a ser así, en el prólogo de ese libro ya daba por cierta su gloria literaria. Se hablará más adelante del éxito que obtuvo el libro gracias a la concesión del Premio Nobel. La segunda edición incluía ya esa noticia; desnuda porque no sería hasta dos meses después cuando tendría lugar la ceremonia de entrega de la patente de corso que es el Nobel para cualquier escritor. Al morir mi padre trece años después ese mismo libro incorporó nuevos capítulos y, entre ellos, mis recuerdos de lo que fue la entrega del Premio Nobel. Creo que el mejor homenaje que puedo hacerle hoy en esta revista a Camilo José Cela (CJC solía llamarse a menudo a sí mismo) es rescatar aquellas páginas olvidadas ya.
\end{abstract}

Palabras clave: Cela mí padre; Memorias; Centenario CJC

Resumo: Em 1989 escrevi um livro que se chamava Cela mi padre, poucos meses antes de que lhe concedessem o Prêmio Nobel. Mesmo sem saber que ia acontecer, no prólogo desse livro eu já dava por certa sua glória literária. Mais adiante tratarei do êxito que obteve o livro graças à concessão do Prêmio Nobel. A segunda edição já incluía essa notícia; desnuda porque não seria até dois meses depois quando ocorreria a cerimônia de entrega de "la patente de corso" que inspirou novos capítulos e, entre eles, minhas recordações do que foi a entrega do Nobel. Creio que a melhor homenagem que posso fazer hoje nesta revista a Camilo José Cela (CJC costumava chamar-se a si mesmo muitas vezes) é resgatar aquelas páginas já esquecidas.

Palavras-chave: Cela mí padre; Memórias; Centenário CJC

Abstract: In 1989 I wrote a book called Cela mi padre, a few months before to grant him the Nobel Prize. Even without knowing what would happen, in the prologue of this book I already took for granted his literary glory. Further treat the success enjoyed by the book thanks to the award of the Nobel Prize. The second edition already included this news; naked because it was not until two months later when there would be a ceremony of "la corso patent which inspired new chapters and among them, my memories of what was the delivery of the Nobel. I believe that the best tribute we can do today in this magazine Camilo José Cela (CJC used to call himself often) is to rescue those pages already forgotten.

Keywords: Cela mí padre; Memoirs; Centenary CJC

El mismo título de estas cuartillas, aunque sin la coma (las razones editoriales mandan), fue el de un libro que escribí en 1989, pocos meses antes de que le concediesen el Premio Nobel a Camilo José Cela. Sin saber que iba a ser así, en el prólogo de ese libro ya daba por cierta su gloria literaria.

Se hablará más adelante del éxito que obtuvo el libro gracias a la concesión del Premio Nobel. La segunda edición incluía ya esa noticia; desnuda porque no sería hasta dos meses después cuando tendría lugar la ceremonia de entrega de la patente de corso que es el Nobel para cualquier escritor.

Al morir mi padre trece años después ese mismo libro incorporó nuevos capítulos y, entre ellos, mis recuerdos de lo que fue la entrega del Premio Nobel. Creo que el mejor homenaje que puedo hacerle hoy en esta revista a Camilo José Cela (CJC solía llamarse a menudo a sí mismo) es rescatar aquellas páginas olvidadas ya. Aunque me permitiré añadir un estrambote. 


\section{Padre nuestro, que estás en los cielos}

El jueves diecinueve de octubre del año mil novecientos ochenta y nueve, mientras estaba yo dando mi clase de antropología en la facultad de letras de Palma, dos compañeros del departamento entraron de golpe en el aula dando gritos:

- ¡El Nobel! ¡A tu padre le han dado el premio Nobel!

Como no soy partidario de mezclar la vida personal con el trabajo de profesor, les pedí que me esperasen fuera mientras terminaba la clase. A decir verdad, no me resultó sencillo aunque sólo fuese porque a los alumnos les interesaba mucho más lo otro; ya se sabe que la ciencia es poco apreciada en España.

Una noticia así es de las que hacen que el corazón te dé la vuelta. Pero a mí me había llamado una hora antes Juan Cruz desde Madrid para decirme que el rumor del Nobel era insistente, así que tampoco me cogió de sopetón del todo. Al terminar la clase, ahí fue Troya. Apenas sí podía atender a los abrazos, al teléfono, a las insistentes demandas de los periodistas... Si se tienen en cuenta las muy escasas veces en que se ha honrado a nuestro país con el Nobel, resulta lógico. Pero ninguna lógica podía prepararme para lo que vendría después.

La primera edición de este libro salió a la calle al día siguiente, el veinte de octubre de 1989. Un reportero sagaz me preguntó si lo había escrito en una noche - escrito, corregido, picado, maquetado, impreso, encuadernado y distribuido, por supuesto. Le contesté que no, que era al revés, que había llamado a Estocolmo para decir a los académicos que no concedieran el premio hasta que yo terminase Cela mi padre.

Quizá sea éste un buen lugar para aclarar que, tras haber rematado el manuscrito, allá por la primavera de ese mismo año y en los mismos días en que nacía mi hija Camila, se lo pasé a mi padre. Lo recibió con cierta sospecha. Le preocupaba no poco que hubiese aprovechado la oportunidad para llevar a cabo una especie de ajuste de cuentas con él. Los lectores del libro podrán juzgar acerca de si así es o no pero él se quedó lo bastante satisfecho como para no decirme nada. Alejen toda sospecha acerca de una actitud así. Cuando le di a mi padre otro de mis libros, uno de filosofía de la biología que se llama De genes, dioses y tiranos, leyó por encima un par de párrafos, lo cerró y me lo devolvió diciéndome:

- Está en alemán.

La editorial había pensado en sacar Cela mi padre hacia las navidades, pero anticipó de inmediato su exhibición en los mostradores. Acertó, porque la primera edición se agotó en un día. Salieron luego hasta seis más sin cambiar otra cosa que el prólogo, para dar fe de la concesión del premio Nobel. Ahora esta nueva versión añade dos capítulos, éste y el que remata el libro, amén de algunos retoques levísimos y mínimos allí donde han sido necesarios.

El ascenso a los cielos de mi padre se refiere al ámbito internacional; en el Olimpo español llevaba ya instalado hacía bastantes años. Pero la dificultad de traducir el estilo de CJC a otras lenguas le había negado el favor de la extranjería. Algunas de las reacciones a la concesión del premio fueron geniales. La más divertida de todas fue, creo, la de Graham Greene quien, al preguntarle qué opinaba de la concesión del Nobel a Cela, contestó:

- ¿Cela? ¿Es "él” o "ella”?

Greene se sumó a la larga lista de autores que se quedaron de una manera del todo injusta sin el premio. Pero nada de eso importó a los celianos que, de inmediato, convirtieron la noticia en un puro desmadre. Eso es lo que tiene el vivir en un país como España que ignora cualquier sentido de la medida, para lo bueno y para lo malo. Pero si me asombró la reacción hispana es porque no me podía ni imaginar lo que iba a suceder cuando la entrega del premio en Estocolmo.

Ese episodio, el de la ceremonia sueca, coincidió con el testimonio más grande de la entereza y la generosidad de mi madre. La mujer de Camilo José Cela, esa Charo que le había acompañado en los momentos peores, en los años de las dificultades de todo tipo, en los tiempos de la miseria, y de la que se había divorciado poco antes, renunció a estar en Estocolmo para no amargarle ni lo más mínimo a mi padre el instante más feliz de su vida. Hace falta mucha entereza, mucha virtud y, sobre todo, muchísimo amor para tomar una decisión semejante.

\section{Llegada a Estocolmo}

Llegamos a Estocolmo a mediados de diciembre, con la cabeza llena de interrogantes que una circular del ministerio sueco de Asuntos Exteriores, en castellano perfecto, se encargó de contestar en parte. Cada galardonado disponía de un funcionario a su servicio y a mi padre, por aquellas casualidades que reserva la vida, le asignaron a Linda Corugedo-Sternberg, mujer de Víctor Corugedo, quien a su vez era primo nada menos que de Fernando Corugedo, el secretario los últimos tiempos mallorquines de mi padre. La circular describía con nórdica meticulosidad todos los pasos a dar entre el 6 de diciembre y el 10, día de la ceremonia, aunque las normas se prolongaban hasta el día 13 . Se conoce que era ése el límite previsto de la paciencia de los organizadores.

Estocolmo recibió a su nuevo premio Nobel con curiosidad, primero, miedo luego y, por fin, alivio y encanto. Las novelas más importantes de CJC (La familia de Pascual Duarte, San Camilo, 1936) estaban traducidas al sueco desde tiempo atrás pero el editor de los libros 
de mi padre, Kjele Peterson, me confesó que de $L a$ colmena, título con el que se inauguró la casa Atlantis, se habían vendido sólo diecinueve ejemplares. El panorama cambió por completo a raíz del premio. Mazurca para dos muertos, publicada después de tres años de difícil traducción, agotó diez mil ejemplares en poco tiempo. Quizá la manera de tratar a la figura del escritor español en los diarios suecos, casi como si se tratase de un personaje de fábula, contribuyó al éxito aunque fuese tarde.

Ese fervor generó también expectativas no satisfechas. Estocolmo aguardaba la llegada de un autor tremendo, disfrazado de revolucionario de los de antes de Marcuse, y se encontró con un señor que jamás aparecía en público sin corbata, sombrero y abrigo oscuro, con alguien como sacado de los armarios de la embajada. Por fortuna la tropa de acompañamiento de Cela puso las cosas en su sitio muy pronto, para alivio de quienes creían que se había premiado a un escritor equivocado. Los corresponsales venidos de España tomaron por asalto el Grand Hotel de Estocolmo, residencia oficial de los premiados. Se trata de un edificio enorme volcado sobre uno de los numerosos brazos de mar de la ciudad y, en sus salones de un cuidadosísimo y recargado clasicismo, se celebraba cada día la ceremonia de la desesperación. En el Grand Hotel, entrando y saliendo de la habitación 468 -non smoking-, fui testigo directo del drama. Allí no pasaba nada que los cronistas pudiesen narrar, ni aparecía nadie que mereciese el gastar el negativo de una foto. Como, rendido por el tedio, siempre había algún reportero que disparaba su flash sobre el hijo de un cuñado de un primo hermano de Cela, hacia allá acudía la nube de periodistas en busca de la noticia. Luego volvían a la languidez de los sofás inmensos. Fuera, entretanto, nevaba, y el cielo se oscurecía aún más convirtiendo el poco día en penumbra. Momentos así hicieron caer a Poe en el opio pero, en Estocolmo, apenas había más alivio que el del Aquavit al que echar mano. Un crimen pasional, o incluso una pequeña historia de celos, hubiese arreglado algo la monotonía de los actos oficiales y los discursos.

\section{Los preparativos}

La jornada del día diez de diciembre era, faltaría más, el centro de todas las atenciones, el momento aguardado por los expedicionarios. Es adecuado entrar en el túnel del tiempo y volver a vivir las horas que enmarcaron aquella fecha memorable.

Se podría empezar diciendo que el día más grande en la vida de un premio Nobel comienza pronto, pero no es cierto. La amanecida, cuando nieva en Estocolmo, apenas significa un leve cambio en la neblina del cielo gris. En los días claros de invierno el sol levanta cosa de una cuarta sobre el horizonte, pasa luego rozando la copa de los árboles como un enamorado en busca de cobijo, duda un instante y acaba por hundirse, entre tímido y confuso, en esa noche de la que le cuesta tanto salir. Si la nieve está cayendo, la bruma convierte el día en una metáfora. Los relojes de las calles de Estocolmo deberían llevar marcadas las veinticuatro horas, y no sólo doce, para dar a sus agujas una pista acerca del camino que han de recorrer.

A las once en punto de la mañana, con una precisión que los bálticos convierten en enfermizo esmero, los galardonados con alguno de los premios Nobel que entrega el rey de Suecia, es decir, los de Química, Física, Medicina, Economía y Literatura, tienen ensayo. El premio de la paz, instituido por el parlamento noruego, se concede y celebra en Oslo, así que escapa a la representación colectiva. Bien que lo lamentó Camilo José Cela, quien confesaba, añorante, que le hubiera gustado mucho hacer su entrada en el escenario llevando en brazos al Dalai Lama. No pudo ser y, por mucho que el espectáculo perdiera así grandeza, habrá que alegrarse de haberle ahorrado al presidente de la fundación Nobel, maestro de ceremonias durante el ensayo, un inoportuno y prematuro infarto.

Dejando de lado, pues, la paz noruega, los laureados del resto de las disciplinas premiables deben acudir al gran auditorium del Konserthusets de Estocolmo para aprenderse bien aprendido el ritual mediante el que, horas más tarde, serán ungidos con el óleo de la gloria. Allí se les explica cómo debe levantarse, lleno de majestuosidad y aplomo, un premio Nobel en ciernes; cómo acepta luego el diploma y la medalla que acreditan su rango; cómo ha de saludar, y por qué orden, al rey, a la Academia y a los invitados al acto; cómo, por fin, vuelve al sillón que abandonó poco antes sin mostrar ni la menor emoción por haberse incorporado ya a la nómina de los inmortales. Se desaconsejan los saltos mortales de alegría y los saludos con dedicatoria a mamá, que me estará escuchando.

Los asistentes de a pelo a la ceremonia, es decir, los parientes, los amigos o los afortunados curiosos que pueden hacerse con alguna de las limitadísimas invitaciones, no ensayan. Y lo cierto es que deberían, al menos, recibir alguna que otra indicación sobre lo que les aguarda. Las que figuran en el programa apenas sirven de nada: hace ya tiempo que los viajeros procedentes de tierras lejanas hemos aprendido la importancia de la puntualidad. Nadie le advierte a uno, sin embargo, de ciertos riesgos y muy cumplidas amenazas. Vestirse con un frac, por ejemplo, obliga a combinar la paciencia, el malabarismo y el ingenio en grandes dosis antes de dar con la adecuada combinación de botones, pasadores, presillas, tirantes, gomas y gemelos que acaban componiendo a la postre una imagen quizá digna, pero envarada como la que más. Quien sobrevive a la pechera almidonada, 
al calzado de charol, al cuello duro, al chaleco entre ortopédico y glamoroso y al mísero y falso corbatín, puede encontrarse con la sorpresa de que se ha dejado sin anudar los cordones de los zapatos. Intentar hacerlo ahora, con la armadura a cuestas, conduce de inmediato a una hernia de disco. Los ayudas de cámara ya no existen. Insisto: el libro de instrucciones no vendría nada mal.

Tampoco sabe uno que, salvo los galardonados con el premio -a los que conviene conservar vivos hasta que acabe el día $\mathrm{o}$, más bien, la noche- todos los demás serán abandonados a su suerte lejos de los locales en los que se aplaude, se brinda, se mastica y se baila en memoria de don Alfredo Nobel. La comitiva de torturados y, aun así, alegres conmilitones tiene que desfilar por las calles repletas de una nieve a la que el paso de los automóviles ha convertido ya en fango. Los zapatos de raso, los vestidos largos y los brillos del charol terminan allí mismo su gloria. Pronto se definen dos grupos: el del equipo local curtido ya en muchos años de batallas con la inclemencia, que, al abrigo de las botas de goma y las pieles, alcanza pronto el vestíbulo de turno, y aquél de la turbamulta de extranjeros, casi todos hispánicos en esta ocasión, que pasea sus miserias levantando faldas y esquivando charcos en busca de dónde poner el pie.

\section{La ceremonia}

Cinco horas y media después del ensayo, en el minuto preciso, comienza la función. La sala de conciertos, de una modernidad que recuerda la de los años cincuenta del pasado siglo, está presidida por un órgano inmenso al que se sube por una escalera metálica de caracol. El palco para la orquesta domina el gran escenario al que alumbran de forma cruel las luces, las sempiternas luces, impuestas por la servidumbre de la televisión. Cada rincón disponible está cubierto de flores amarillas y anaranjadas que ha enviado la Azienda di Soggiorno e Turismo de San Remo.

Las señoras de traje largo y caballeros atormentados por el frac, se levantan cuando aparece la infanta Cristina, armada de una juventud a la que apenas afecta el protocolo. Hay que ponerse de nuevo en pie al hacer su entrada en el escenario los reyes Silvia y Gustavo de Suecia acompañados de los augustos tíos del último. $\mathrm{Y}$ se debe abandonar una vez más el asiento cuando la orquesta ataca la Festmarch de Hugo Alfvén y los laureados con el premio Nobel -nueve en total, porque el de Física, Química y Medicina están compartidos este año- ocupan sus puestos. Con tanto levantarse y sentarse uno ha aprendido ya a mover las colas del frac como si fueran propias, pero sin la elegancia y desinterés que muestran los académicos suecos. Se conoce que están más acostumbrados a la gimnasia.
La ceremonia sigue con la sucesión de piezas de Mozart -cantadas por Anne Sofie von Otter- y Strauss que da paso a los discursos en los que se resumen los méritos de cada uno de los premiados. Durante el ensayo se les había advertido a éstos que no debían sobresaltarse con el primer compás de la Explosionspolka de Strauss, que hace honor al nombre. Pero nadie debió avisar a la reina Silvia que, como todo el mundo, pega un respingo al oír el golpe inicial de los timbales; se ve que tiene muchas tablas porque termina por hacerle mucha gracia su propio susto.

El programa del concierto está elegido con mucho cuidado para honrar de la forma más imparcial posible a los diversos sabios galardonados, pero Camilo José Cela tendrá derecho a una tonada propia: "Los vecinos", de $E l$ sombrero de tres picos de Manuel de Falla. Poco habrá de importarle a él, que es sordo en todo lo referente a la música y es posible que la confundiese con una canción folklórica esquimal. En lo que hace al resto, cada uno de los galardones sigue una misma y cuidada ceremonia, por más que haya peculiaridades interesantes. Sólo nuestro premio Nobel de Literatura, por ejemplo, luce medallas: la de la Real Academia de la Lengua, la Gran Cruz de Isabel la Católica y la de la Villa de Padrón. Sólo él viste chaleco y corbatín negros, de acuerdo con la costumbre de los académicos españoles. Sólo CJC permanece todo el tiempo con el gesto ceñudo habitual de quien parece enfadado con el mundo, sin leer la traducción de los discursos suecos que, por otra parte, está en inglés excepto en su propio caso. Sólo el cronista oficial de Padrón se guarda con esmero de dar la espalda al rey, luego de recibir la caja del diploma. Camilo José Cela es ya premio Nobel a todos los efectos. El aplauso, atronador, muestra bien a las claras a quién sigue el público asistente al acto. La emoción se desborda y hasta el hierático CJC, una vez sentado, se permite, contraviniendo todas las reglas, un tímido saludo a la concurrencia. Al terminar el acto, es el delirio. Pocos pueden a esas alturas contener las lágrimas.

\section{El banquete}

Pero enfriar las emociones, en Estocolmo, cuesta poco.

Una nueva odisea por caminos de nieve, jalonados esta vez por unos misericordiosos boy-y girl-scouts que sostienen antorchas en una larga fila, conduce a otro lugar, el enorme Salón Azul del ayuntamiento de Estocolmo, extraña muestra de un eclecticismo que une el ladrillo visto, la bóveda de hormigón, el falso techo de escayola y los vidrios emplomados. El escenario en que se va a dar cuenta del banquete en memoria de Alfredo Nobel. Algunos consiguen llegar allí en tan buen estado como para animarse a acudir al cuarto de baño. Los más se 
refugian en la multitud, buscando un poco del calor que ya nadie recuerda. Pero no hay que permitir que decaiga el ánimo. Está a punto de celebrarse la comida más famosa del mundo de las ciencias, las artes y las letras.

El ceremonial sigue siendo, por supuesto, rígido y exacto. Por poner un ejemplo, los brindis anunciados tendrán lugar a las siete y cinco y a las siete y siete de la larga noche. Inútil es decir que, aun cuando nadie mira el reloj, los segundos son tenidos muy en cuenta. Hasta la nube de camareros actúa al unísono, dirigida por un maestro de ceremonias al que así, a ojo de buen cubero, cualquiera tomaría por un secretario de embajada como poco.

Del techo del salón cuelgan hasta trece lámparas de araña entre estucados de oro y columnas corintias que enmarcan los escudos de armas. En las esquinas, altorrelieves en escayola y bustos de un material impreciso. Los asientos son bancos de iglesia forrados de terciopelo azul. El suelo, como el parquet gastado de un salón de baile. A mi lado se sienta una hija del premio Nobel de Química, que me comenta que somos colegas. Hasta ahí podíamos llegar, le replico:

- ¿Cuantos hermanos son ustedes?

- Tres. Somos tres hermanos

- Y el premio de Química lo comparten dos profesores. Dos por tres son seis. Le corresponde a usted una sexta parte.

El paté de anguilas, la espalda de alce y la juliana de legumbres son un digno marco para el momento culminante del banquete, cuando Rostropovitch, armado del cello, dedica su música a la memoria de Boris Pasternak, al escritor tan insumiso como excelso a quien un gobierno algo más estúpido que los demás le impidió recoger su premio. Luego la ceremonia y el protocolo se relajan algo con la versión nórdica de la tuna de los estudiantes de Derecho. Se conoce que los suecos no acaban de ver del todo bien esa historia, porque se han ido hasta Noruega en busca de los saltimbanquis.

Los discursos de los laureados devuelven emoción y empaque. En medio de un silencio sepulcral, va a leer Camilo José Cela unas palabras -tres minutos como máximo, ordena el programa- que ya han sido más que aireadas en todas las lenguas. Incluso los que no entienden el castellano, que son mayoría, se conmueven con el vozarrón profundo y sereno que va predicando paz a los hombres de buena voluntad.

El resto de la ceremonia pertenece a la categoría de la anécdota. Un baile en el que el protocolo pierde su sentido, unas recepciones privadas con los reyes suecos y un enorme cansancio generalizado se acumulan cuando la noche todavía camina cerca de su primera mitad. El sombrero de tres picos y la capa española de Camilo José Cela duermen en el inmenso vestuario. Su premio Nobel, ese premio Nobel que guardó bajo el brazo, aferrándolo de una forma reñida con la etiqueta cuando el rey de Suecia le entregó el galardón, ya no es suyo. Es de los que estuvieron presentes en el salón de conciertos, de los que encontraron un lugar a la mesa del banquete, de los que siguieron los actos en las pantallas gigantes habilitadas para quienes no cabían, de los amigos y de los enemigos próximos y lejanos. El Nobel es ya, cuando ni siquiera apunta el nuevo día, de todos nosotros.

\section{Los entresijos}

La entrega del premio en Estocolmo fue, una vez más, un compendio de luces y sombras en la vida siempre agitada y contradictoria de CJC. La polémica-cómo nole acompañó hasta el Konserthusets. La ausencia del ministro de Cultura, Jorge Semprún, marco el principio del distanciamiento de mi padre con los socialistas, aunque no de todos: otro ministro, Barrionuevo, siguió contándose entre sus amistades hasta el extremo de incorporar a CJC al consejo de administración de la RENFE. Siento horrores que las normas de las juntas me impidiesen asistir a alguna las reuniones porque me hubiera encantado espiar por un agujerito de las cortinas para ver lo que dice un escritor en el corazón de las grandes empresas. Quizá se limitase a pedir de vez en cuando agua porque, si tenía que combatir el curioso modo de utilizar el castellano de los altos ejecutivos, siempre dispuestos a presupuestar en vez de presuponer y con la muletilla del "a nivel de" sonando de continuo en el discurso, no es raro que terminase falto de saliva y con los oídos llenos de zumbidos.

Son muchas otras, además de las del desprecio de la cultura oficialista de entonces, las anécdotas que se sucedieron en Estocolmo. La legión de los amigos de CJC, organizada por clanes tribales -los gallegos, los mallorquines, los alcarreños, los de Marbella, y asítomó por asalto la ciudad hasta tal punto que me temí la intervención del ejército para poder dejar las cosas en un más sosegado término. Los suecos ignoraban la versión del testimonio de amistad en forma de cuerpo expedicionario, quizá porque las legiones de Julio César no llegaron tan al norte. Difícil era ir a cualquier restaurante, ya fuese lujoso o no, sin encontrar una turbamulta de españoles husmeando con desconfianza los platos del Smorsgabord, si es que se escribe así esa colección de entremeses en la que hay arenques, arenques, arenques y algún que otro adorno acompañándolos. El último día, cuando ya nos salían los arenques por las orejas, descubrimos que existe una magnífica cocina sueca basada en la caza. A buenas horas, mangas verdes.

La embajada española en Estocolmo organizó para la noche del siete de diciembre una recepción muy fina, 
como corresponde a las fiestas del cuerpo diplomático, que tuvo, no obstante, un par de inconvenientes. El primero, que allí no había canapés suficientes para el gentío enorme que acudió a la cita, cosa, por otra parte, de menor importancia. Más grave fue que no se hubiese previsto la repatriación de los invitados. La embajada, un palacio en medio de los bosques de la capital, no disponía, claro es, de parada de autobús ni de metro, y los taxis eran imposibles de encontrar en aquella noche gélida del diciembre sueco. Había que arreglárselas, pues, como fuera, dando suelta a la imaginación para volver a la ciudad con los zapatos y los vestidos de gala arrastrándose por la tundra. La única alternativa consistía en pedir asilo diplomático allí, cosa harto difícil de lograr cuando uno tiene pasaporte del mismo país que la embajada. A nosotros, a mi mujer y a mí, nos salvó Leopoldo Calvo Sotelo, el antiguo presidente del Gobierno quien, por cierto, es una de las personas con sentido del humor más fino y más agudo que he conocido. Se apiadó de nosotros y nos hizo un hueco en su coche.

Las revistas rosa persiguieron a toda la familia y sus allegados en las diversas fiestas con el ansia de un hurón que ha husmeado el rastro de la presa. Algunos de los comentarios que se escribieron entonces fueron muy divertidos. Resulta que quien era entonces $\mathrm{mi}$ mujer, Gisèle, había metido en la maleta un traje largo de Jesús del Pozo para las ceremonias y, como el diablo anda siempre al acecho, hubo otra persona del entorno cercano de CJC que tuvo la mala suerte de comprar el mismo vestido. Gisèle es suiza, alta, muy alta, y rubia, muy rubia. En la recepción dada por la editorial Atlantis unos días antes de la entrega del premio, el secretario de la Academia sueca le dijo que parecía mentira, pero que desde que España había entrado en el Mercado Común las mujeres españolas se parecían cada vez más a las europeas. Añadiré de inmediato que es catedrática de psicología y publica artículos en las revistas de impacto de esa ciencia, pero nada de eso le interesaba de los cronistas. Por el contrario, cuando vieron aparecer en la recepción de la embajada a las dos mujeres vestidas igual, se permitieron escribir maldades tremendas acerca de cómo les sentaban los diseños de Jesús del Pozo a cada una de ellas.

Ya fuese por esa razón o por otras de mayor calado, en Estocolmo se insinuó -se trata de un eufemismo- una escisión en la corte de CJC entre los viejos amigos y los nuevos. No fueron pocos aquellos de los amigos de toda la vida que se extrañaron ante una acogida más bien fría y distante. Yo, con mi falta de entendederas de costumbre, ni me enteraba. Pero a la hora de irme, cuando la despedida final de mi padre, me cayó la venda de los ojos. Era en el Grand Hotel, con CJC en medio de la corte. Le abracé pero, como pude recordar años más tarde en ocasión de su muerte, no estoy seguro de haber recibido un abrazo de vuelta. Son cosas que pasan, ya lo sé, no hace falta que me lo diga nadie.

\section{Fiesta en la Bonanova}

Los amigos de siempre y, sobre todo, los de Mallorca se dieron cuenta mucho antes que yo de lo que sucedía, así que me correspondió, una vez más, salir al ruedo para alejar a capotazos una sensación desagradable de olvido. A todos ellos les convocó mi madre en la casa de la Bonanova y allí, mientras se me preguntaba por los mil y un detalles de la ceremonia de Estocolmo, leí unas palabras que reproduzco aquí:

\begin{abstract}
"Ante la ausencia de Dios padre, me corresponde a mí oficiar de sumo sacerdote. Si tenemos en cuenta cómo acabaron, de Mahoma al Bautista, todos los profetas, no resulta ése un papel demasiado aconsejable. Confiemos en que, por lo que hace a mi caso, las cosas rueden algo mejor.
\end{abstract}

Todos los ahora presentes fuisteis testigos fidelísimos de las andanzas de Camilo José Cela por tierras mallorquinas. Aquí, desde Pollensa a La Bonanova, acertó mi padre a escribir los libros que, con mayor o peor fortuna, le fueron llevando por los caminos de las glorias mundanas y, a la postre incluso por aquellos de las celestiales. A lo largo de todos esos años CJC estuvo rodeado de gentes que le querían y no se recataban en demostrárselo. Sería probablemente absurdo suponer que sin vosotros, sin sus amigos, la obra del premio Nobel no hubiera tenido lugar, pero lo cierto es que habría sido diferente. Más o menos extensa, pero diferente. Demos gracias por ésta de ahora mismo, por la que tenemos a nuestro alcance y por la que pasará a la historia para deleite y sosiego de los futuros lectores de Cela.

Sé bien que vosotros, durante esos años, habíais pensado en acompañar a Camilo José Cela a recoger un premio que a nadie se le hacía ni lejano ni improbable. Llegado el momento, las cosas han transcurrido de manera distinta. Por mor de las férreas reglas del protocolo vikingo, CJC no ha podido llevar, como quería, un avión lleno de sus amigos mallorquines. Pero no tiene ningún sentido el dolerse $\mathrm{y}$, menos todavía, en una ocasión tan gozosa como ésta. Lo que importa de verdad es recordar precisamente ahora que nadie, salvo vosotros, tuvo la oportunidad de conocer y amar al vagabundo en aquel entonces, mucho antes de que los azares de la fortuna acabasen por elevarlo a los altares.

Camilo, el mozo. La Bonanova, a trece de diciembre de 1989."

De esas palabras se hizo un folletón impreso en los talleres de la Antiga Impremta Soler, de Palma. En la cubierta se reproducía el esbozo que mi padre había 
hecho del Liberal y mundial cabildo de caballeros $e$ infantes de la tabla redonda de la Bonanova, orden no sé si militar o monástica que llevaba, en el dibujo, la fecha tachada de MCMLXV y se dividía en dos instituciones, Gobierno y Senado, a las que se añadían la Nómina de caballeros parciales, la Nómina de infantes parciales, La Junta de damas y el Gallinero de malditos. Me aterra pensar en qué cesto hubiera caído mi nombre si mi padre hubiese completado el proyecto. Pero sólo el Gobierno y el Senado incluían algunas referencias nominales.

El Gobierno comenzaba por el Gran Maestre, adjudicado por CJC a Américo Castro, a quien seguían el Curador -con las iniciales de mi padre- y el Contralor, reservado para José Larraz. Por lo que hace al Senado, constaba en ese cabildo nonato de distintos oficios agrupados en tres bloques: Oficios del capítulo de la cabeza (Actuario, José Roán; Fiel, que quedaba vacante, y Loquero, en el que figuraba, claro, López Ibor), Oficios del capítulo del vientre (refitolero, Néstor Luján; Maestresala, Juan Cárdenas; Sumiller, don Félix Huarte, que era el único de este capítulo a quien se le daba tratamiento) y Oficios del capítulo del corazón (Poeta, Robert Graves; Físico, Juan Rof Carballo y Capellán, donde figuraba, debajo de un nombre tachado a conciencia, Dom Mauro).

Mi padre no fue nunca Curador de esa orden. Terminó siendo marqués, pero eso es algo muy diferente. Marqueses hay muchos. Curador del liberal y mundial cabildo de caballeros e infantes de la tabla redonda de la Bonanova no podía haber más que uno solo.

\section{A título de estrambote}

¿Han sacado ustedes ya su propia conclusión de la forma de ser de Camilo José Cela?

La mayor parte de quienes nos cuentan cómo era mi padre añaden a sus propios recuerdos lo que vieron reflejado en la actitud de CJC. De ahí viene la versión más conocida de lo que fue el gran histrión en el trance de representar el papel de sí mismo. Camilo José Cela compuso un CJC-personaje para consumo público que fue el que adornó en particular sus últimos años de vida pero que apuntaba ya en las primeras entrevistas que acertaron a hacerle apenas comenzada su carrera literaria. Sumemos los trazos: deslenguado, irónico, cruel, ajeno a cualquier pasión, cerebral, chulesco... ¿Me dejo alguna virtud en el tintero? Después, en el día a día, sus amigos más cercanos daban fe de que CJC no era así ni por asomo, que en el trato directo desaparecía esa fiera que se comía un niño crudo por desayuno todas las mañanas para dar paso a una persona mucho más entrañable. Fue ése el padre que yo conocí.
Pero, jay!, se trataba de un escritor. Ya lo he dicho: los novelistas viven de la imaginación. Pobre de quien tome por artículo de fe aquello que meten en sus libros.

En busca del Camilo José Cela auténtico los biógrafos, aficionados o profesionales, han buceado en otras fuentes. Una de ellas es obvia: los dos tomos ya citados de sus memorias, La rosa de 1959 y Memorias, entendimientos y voluntades de 1993, ambos con segundas ediciones ampliadas y prologadas para dejar las cosas en su sitio. La costumbre de dejar los prólogos de lado hace que sirvan de poco pero no debería ser así. En el de la edición ampliada de La rosa CJC nos advierte: "el libro de memorias es menos científico, más arbitrario que la biografía. Su orden no requiere de tanta exactitud y podría imaginarse como un portillo abierto sobre el corazón que se quiere confesar de una manera quizá un tanto turbulenta".

El corazón que se quiere confesar. Pero, ¿de qué pecados? ¿De los reales o de los imaginarios?

Hay un episodio en la vida -real o literaria- de CJC que pone de manifiesto la necesidad de acudir a sus páginas con una lupa de aumento. Se trata de su noviazgo con Toisha Vargas. Toisha aparece en tres libros de mi padre, en dos de ellos con nombre y apellidos (San Camilo, 1936 y Memorias, entendimientos y voluntades) y en el tercero sólo con sus iniciales T.V. (como título de un poema de Pisando la dudosa luz del día). El biógrafo más conocido de Camilo José Cela, Ian Gibson, da por cierta su existencia -aunque se cura en salud poniendo un condicional: "si podemos fiarnos de Memorias, entendimientos y voluntades"- y habla de manera profusa de ella y de su relación con CJC utilizando como pista, más que el libro de memorias, la novela San Camilo, 1936. De allí saca Gibson el verdadero apelativo de Toisha, Tránsito, el por qué de su transformación a otro nombre con aire japonés y la mayoría de las circunstancias que nos llevarían a conocer no sólo ese amor de juventud sino la verdadera personalidad de CJC.

En Memorias, entendimientos y voluntades Camilo José Cela cuenta su boda -fallida- con Toisha de esta forma: "El día de mi santo de 1936, a eso de la 1 de la tarde, probé a casarme con Toisha en casa de Ibarra, Mendizábal, 64, ático C". La boda iba a celebrarse como sigue:

según los usos de la religión inventada por mi amigo Ibarra, la Heredad de los hermanos Mínimos de Zarathustra (...) El rito consistía en que, presididos por dos fotografías, una de Nietzsche y a otra del padre de Ibarra, que eran casi iguales, los novios, desnudos, de pie, uno frente al otro y enlazados de ambas manos, debíamos escuchar a Ibarra, que era el sumo sacerdote, 
leer el artículo de su padre titulado El mago del idioma, publicado en El Nacional de Managua, para después cantar la última estrofa del Himno Nacional de Nicaragua (...) Por último debían besarse, primero el novio a la novia y después al revés, en la frente, en ambos ojos, en ambas orejas, en la nariz, en la boca, en ambos pezones, en el ombligo. en el sexo y en ambos pies, bien entendido que si el novio daba el menor síntoma de estar cachondo, la ceremonia debía repetirse puesto que era inválida.

Recapitulemos: esa boda de acuerdo con los ritos de la Heredad de los Hermanos Mínimos de Zarathustra, frustada a causa de una erección inoportuna del novio -no se dice, pero se supone-, se realizó de acuerdo con CJC a la una de la tarde del día en que comenzaba la guerra civil en España. Bienaventurados sean los biógrafos que dan por buena la historia; de ellos será sin duda el reino de los cielos.

No sé si merece la pena añadir que ninguno de mis tíos oyó jamás hablar de Toisha Vargas, destrozada por un obús en la madrileña calle del Pez "a poco de llegar los nacionales a las puertas de Madrid” y cuyo ojo guardó el escritor incipiente en un frasco con formol durante cuatro o cinco días, siempre que tomemos por cierto lo que dice el segundo libro de memorias de CJC.

La memoria convertida en invención no se refiere sólo a los recuerdos de amores que no existieron. En ese mismo libro autobiográfico, Memorias, entendimientos $y$ voluntades, se cuenta el episodio que llevaría a CJC al hospital militar de Logroño en plena Guerra Civil. Que estuvo allí queda fuera de toda duda; fueron a verle familiares como Manolo Cela, su primo de Tuy -de quien se dirá algo más en breve-y en Mazurca para dos muertos mi padre describe ese hospital con detalles imposibles de salir sólo de la imaginación. Pero el motivo de acabar allí se adentra por otros terrenos mucho más resbaladizos. Tras huir por segunda vez de Madrid para alistarse en el ejército sublevado, el que hoy conocemos como franquista y se decía entonces Nacional,-Gibson pone en duda en su biografía de CJC los pormenores de esas escapadas, que encuentra muy novelescos-el bautismo de guerra de CJC tuvo lugar, de acuerdo con Memorias, entendimientos $y$ voluntades, "cerca de Farlete, en los barrancos de la desnuda y agria sierra de Alcubierre, en el desierto de Los Monegros". Nada más llegar allí, leámoslo en las palabras de CJC: al cabo de un rato, tampoco puedo precisar más, cayó y estalló una bomba lafitte cerca de mí, estaba tumbado en el suelo, si llego a estar de pie me mata, sentí un golpe seco en la nuca y me quedé sin conocimiento, la metralla de una granada de piña se me clavó en el pecho mientras estaba sin sentido, tampoco me produjo demasiado dolor, después de fui despertando, a lo mejor pasó una hora o más, yo tenía cada vez más frío, estaba helado y temblando como una vara verde y empecé a oír pero no podía ver ni habla.

Serían esas, con arreglo a lo que nos dice CJC, las heridas de guerra que le llevaron a ser internado en la sala $8^{\text {a }}$, heridos graves y -atención al dato- enfermos infecciosos, del hospital militar de Logroño. Unas heridas que se recuerdan capítulos después al hablar de "cuando me dieron los dos metrallazos en Alcubierre" y que obligaron al médico a darle por muerto diciéndole a la monja sor Catalina "a este desgraciado (...), para lo que va a durar, déle lo que tenga por ahí".

¿Fue eso lo sucedido? Una vez libre del hospital mi padre se refugió en la casa de León de Pío Cela, su tío ingeniero de caminos a quien después tendría como vecino en Ríos Rosas 54, para viajar más tarde hasta el domicilio de sus primos de La Coruña, los Rodríguez-Losada. A esa casa, la de los tíos de CJC Eduardo Rodríguez-Losada y María Trulock, volvería el escritor a pasar los veranos unos años más tarde, cuando era ya novio de Charo, y desde ella envió a mi madre un montón de cartas de amor. Allí vivió "hasta que acabó la guerra salvo las escapadas al frente, que fueron ya al final." Pues bien, a la familia de León y de Coruña primero y a sus padres y hermanos de Madrid después CJC les contó una historia muy diferente. La razón de su estancia en el hospital había sido una recaída seria de la tuberculosis, cosa de la que dan fe los hermanos de mi padre que aún viven. Y, si los metrallazos en el pecho existieron, lo cierto es que no le dejaron cicatriz alguna.

Pero la distancia que va entre invención y recuerdo en un genio de la literatura no es que sea diminuta; es que no existe. Pobres de los biógrafos que toman al pie de la letra lo que un escritor lega, ya sea por medio de sus novelas o de sus memorias.

Recebido: 16/01/2016

Aprovado: 31/01/2016

Contato: camilo.cela@uib.es 